\title{
Descending aorta dissection with angina treated successfully by stent graft implantation
}

\author{
Piotr Buczkowski ${ }^{1}$, Mateusz Puslecki ${ }^{1}$, Maciej Walczak ${ }^{1}$, Jerzy Kulesza ${ }^{2}$, \\ Jacek Smereka ${ }^{3}$, Lukasz Szarpak ${ }^{4}$, Michal Bocianski ${ }^{1}$, Marek Jemielity ${ }^{1}$ \\ ${ }^{1}$ Department of Cardiac Surgery and Transplantology, Chair of Cardio-Thoracic Surgery, \\ Poznan University of Medical Sciences, Poznan, Poland \\ ${ }^{2}$ Department of Radiology, Poznan University of Medical Sciences, Poznan, Poland \\ ${ }^{3}$ Department of Emergency Medical Service, Wroclaw Medical University, Wroclaw, Poland \\ ${ }^{4}$ Lazarski University, Warsaw, Poland
}

Heart and large vessel damage are present in $30 \%$ of victims in traffic accidents. They constitute the second cause of death among multiple organ trauma patients [1-3]. Thoracic aortic injury (TAI) can occur in $2 \%$ of cases, but almost $90 \%$ die at the scene or in transport. Patients who reach the emergency department and are correctly diagnosed can be saved in $70 \%$ cases. There are no specific symptoms of TAI and up to $50 \%$ of victims present no external signs of chest trauma. Pulse deficit in the left arm or lower extremities, also hypoor hypertension can be observed. In descending aorta injury, nonspecific chest pain may be present; angina pain is very rare [4]. A fracture of the sternum, ribs, or shoulders, as well as hemo- or pneumothorax may indicate chest trauma. In the emergency department, computed tomography (CT) [5], trauma scan, and focused assessment with sonography for trauma are the investigations of choice in all multiple organ trauma patients [6]. In recent years, thoracic endovascular aortic repair with stent graft implantation have become methods of choice in the treatment of descending aorta pathologies, especially traumatic aortic injuries $[7,8]$. These techniques minimize surgical risk, particularly in unstable multiple organ trauma patients with severe clinical status, increasing the conditions for favorable long-term results $[9,10]$.

Special attention should be given to the case of a 21-year-old patient admitted to a regional hospital emergency after a car accident with multiple organ injury confirmed by imaging studies. Frac- tures of both pubic bones, transacetabulum right hip fracture, and transverse fracture of the right femur were found. CT examination of the head did not reveal any pathology; there was no free fluid in the abdomen or pelvis region. On applying pharmacological treatment with antibiotics and an analgesic, and traction for tibial tuberosity $(8 \mathrm{~kg})$, the patient was generally in a good condition. The only disturbing symptom recorded was high blood pressure resistant to antihypertensive drugs and accompanied by coronary pain. Unfortunately, no cardiac enzymes (troponin test, creatine kinase test) were undertaken in this regional hospital emergency department, During the following days, further progression of stenocardial symptoms were observed. The control transthoracic echocardiography after 6 days of hospitalization showed good heart contractility, without any valvular pathology. Owing to good visualization of the descending part of the aorta, thoracic aortic dissection was suspected. Chest CT angiography was performed, which confirmed limited dissection of the descending aorta below the left subclavian artery to a level of persistent coarctation (type B Stanford post-traumatic acute TAI). The patient was transferred to the department of cardiac surgery as an emergency admission. Blood pressure recorded on the brachial artery equaled $200 / 60 \mathrm{mmHg}$ and both femoral arteries were pulseless.

A procedure was performed in a conventional way with a femoral approach, under general anesthesia, in an endovascular room. Both common femoral arteries were surgically exposed. A slight

Address for correspondence: Lukasz Szarpak, Associate Professor, PhD, Lazarski University, ul. Świeradowska 43, 02-662 Warszawa, Poland, tel: +48 500186225, e-mail: lukasz.szarpak@gmail.com 


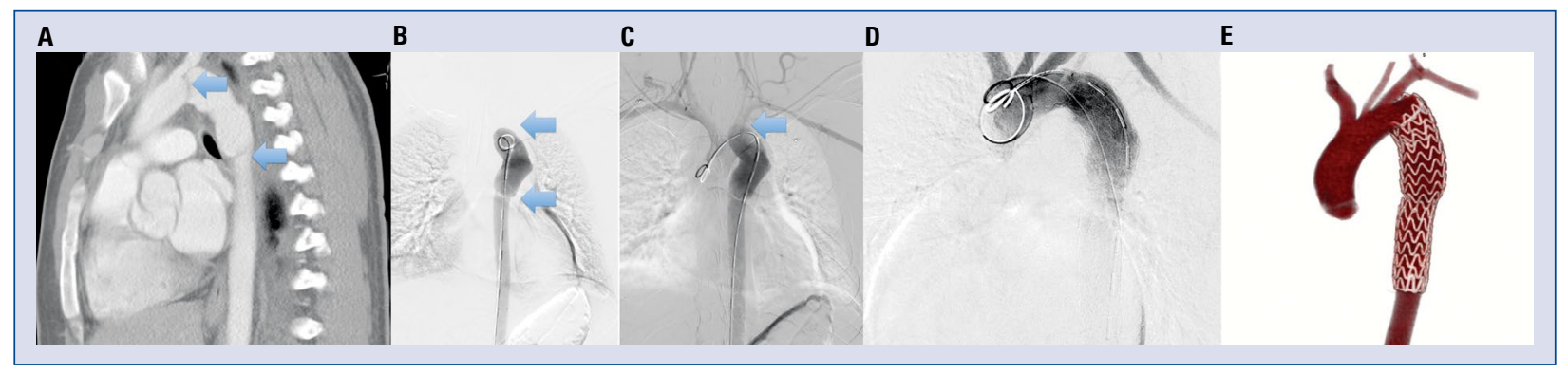

Figure 1. Stent graft implantation; A. Computed tomography angiography: a two-dimensional reconstruction, sagittal cross-section before stent graft implantation. Duplex flap dissection visible; B. Angiography examination: a pigtail in the descending aorta. Abnormal contrast distribution in the descending aorta and dissection flap forming 2 one-direction valves; C. Angiography examination: a pigtail in the ascending aorta. Abnormal contrast distribution in the aorta arch; D. Angiography examination after stent graft implantation. Stent graft expanded, normal contrast passage; E. Computed tomography angiography: a three-dimensional reconstruction.

pulse was confirmed on both sides, with femoral artery systolic blood pressure of $45 \mathrm{mmHg}$.

The left common femoral artery was punctured with the Seldinger's method. A $5 \mathrm{~F}$ pigtail was introduced through a $6 \mathrm{~F}$ catheter straight into the ascending aorta. Before the implantation of the stent graft, angiographic sequences confirmed a short aortic dissection in the descending part. Duplex flap dissection, like a one-way valve, impaired the blood flow in both the systolic and diastolic directions and limited diastolic blood flow to the heart (Fig. 1A-E). This explained the continuous chest pain, resulting from coronary hypoperfusion in diastole caused by blood retention in the upper level of the dissected aorta, as well as problems with the pigtail transition to the aortic arch. The prosthesis was introduced into the thoracic aorta over an Amplatz 0.35 guidewire via a $32 \mathrm{~F}$ GORE catheter. The proximal part of the GORE stent graft $28 \times 150 \mathrm{~mm}$ was introduced just below the orifice of the left subclavian artery (landing zone, LZ-3).

The successful implantation of the stent graft restored normal blood distribution in both the aorta and coronary circulation. In a further hospitalization period, angina symptoms were not reported. After several days, the patient was transferred to a trauma center for continuation of treatment for bone injuries. The patient was evaluated in a cardiac outpatient clinic every 3 months, and is now in good condition after 4 years. The latest CT examination revealed correct prosthesis position and function, with no leakage.

Conflict of interest: None declared

\section{References}

1. Buczkowski P, Puslecki M, Stefaniak S, et al. Post-traumatic acute thoracic aortic injury (TAI)-a single center experience. J Thorac Dis. 2017; 9(11): 4477-4485, doi: 10.21037/ /jtd.2017.10.104, indexed in Pubmed: 29268517.

2. Olasinska-Wisniewska A, Grygier M, Lesiak M, et al. Short- and mid-term outcome of transcatheter aortic valve implantation in patients with advanced age. Cardiol J. 2017; 24(4): 358-363, doi: 10.5603/CJ.a2016.0093, indexed in Pubmed: 27747858.

3. Tagami T, Matsui H, Horiguchi H, et al. Thoracic aortic injury in Japan--nationwide retrospective cohort study. Circ J. 2015; 79(1): 55-60, doi:10.1253/circj.CJ-14-0916, indexed in Pubmed: 25399756.

4. Fattori R, Russo V, Lovato L, et al. Optimal management of traumatic aortic injury. Eur J Vasc Endovasc Surg. 2009; 37(1): 8-14, doi: 10.1016/j.ejvs.2008.09.024, indexed in Pubmed: 19008125.

5. Chmielecki M, Jaguszewski M, Strozyk A, et al. Giant venous graft aneurysm identified by coronary angiography and threedimensional computed tomography angiography. Cardiol J. 2016; 23(5): 554-555, doi: 10.5603/CJ.2016.0077, indexed in Pubmed: 27723061.

6. Treptau J, Ebnet J, Akin M, et al. Angiographic detection of fatal acute aortic dissection Stanford type A under resuscitation. Cardiol J. 2016; 23(6): 620-622, doi: 10.5603/CJ.2016.0103, indexed in Pubmed: 27976792.

7. Antiochos P, Monney P, Fournier S, et al. Endovascular management of heavily calcified abdominal aorta dissection during transcatheter aortic valve implantation. Cardiol J. 2016; 23(6): 655-656, doi: 10.5603/CJ.2016.0107, indexed in Pubmed: 27976796.

8. Puślecki M, Buczkowski P, Perek B, et al. Hybrid procedures for aortic arch repair. Kardiochir Torakochir Pol. 2011; 8(4): 438-444.

9. Criado FJ, Clark NS, Barnatan MF. Stent graft repair in the aortic arch and descending thoracic aorta: a 4-year experience. J Vasc Surg. 2002; 36(6): 1121-1128, doi: 10.1067/mva.2002.129649, indexed in Pubmed: 12469042.

10. Mitchell RS, Ishimaru S, Ehrlich MP, et al. First International Summit on Thoracic Aortic Endografting: roundtable on thoracic aortic dissection as an indication for endografting. J Endovasc Ther. 2002; 9 Suppl 2: II98-I105, indexed in Pubmed: 12166849. 